\title{
PRODUTIVIDADE DE ARROZ IRRIGADO E EFICIÊNCIA DA ADUBAÇÃO NITROGENADA INFLUENCIADAS PELA ÉPOCA DA SEMEADURA ${ }^{(1)}$
}

\author{
Thais Fernanda Stella de Freitas ${ }^{(2)}$, Paulo Regis Ferreira da Silva ${ }^{(3)}$, \\ Carlos Henrique Paim Mariot ${ }^{(4)}$, Valmir Gaedke Menezes ${ }^{(4)}$, Ibanor \\ Anghinoni ${ }^{(5)}$, Christian Bredemeier ${ }^{(6)}$ \& Vladirene Macedo Vieira ${ }^{(7)}$
}

\section{RESUMO}

O potencial de rendimento de grãos de arroz irrigado, semeado em época tardia, constitui-se em informação importante para os produtores. Lavouras semeadas fora da época recomendada têm produtividade limitada pelas condições climáticas desfavoráveis. O objetivo deste trabalho foi avaliar o rendimento de grãos e a eficiência técnica, econômica e agronômica do $\mathrm{N}$ aplicado em cobertura de arroz irrigado, semeado no mês de dezembro no Estado do Rio Grande do Sul. O experimento foi realizado no ano agrícola 2005/2006, em Cachoeirinha, RS. Os tratamentos constaram de duas épocas de semeadura, uma considerada preferencial (novembro) e outra tardia (dezembro), quatro doses de $\mathrm{N}$ em cobertura $\left(0,60,120\right.$ e $180 \mathrm{~kg} \mathrm{ha}^{-1}$ de $\left.\mathrm{N}\right)$ e quatro densidades de semeadura $(50,100,150 \mathrm{e}$ $200 \mathrm{~kg} \mathrm{ha}^{-1}$ de sementes). O delineamento experimental foi o de blocos casualizados, dispostos em parcelas subdivididas, com três repetições. O rendimento de grãos e a resposta à adubação nitrogenada em cobertura foram menores na época tardia em relação à preferencial. As doses de máxima eficiência técnica e econômica diminuíram com o atraso da época de semeadura, e a eficiência agronômica do $\mathrm{N}$ aplicado em cobertura diminuiu com esse atraso e com o incremento da dose. $\mathrm{O}$ número de panículas $\mathrm{m}^{-2}$ foi um dos componentes de rendimento mais limitante

\footnotetext{
(1) Parte da Dissertação de Mestrado do primeiro autor, apresentada ao Programa de Pós Graduação em Fitotecnia da Universidade Federal do Rio Grande do Sul - UFRGS, realizada com apoio financeiro da FAPERGS (Proc. $\mathrm{n}^{\circ}$ 05/2164). Recebido para publicação em maio de 2008 e aprovado em setembro de 2008.

(2) Pesquisadora do Instituto Rio Grandense do Arroz - IRGA. Caixa Postal 29, CEP 94430-030 Cachoeirinha (RS). E-mail: thais@redemeta.com.br

(3) Professor Colaborador Convidado do Departamento de Plantas de Lavoura, Faculdade de Agronomia, UFRGS. Bolsista do CNPq. E-mail: paulo.silva@ufrgs.br

(4) Pesquisador do Instituto Rio Grandense do Arroz - IRGA. E-mail: irgafito@via-rs.gov.br

(5) Professor Colaborador Convidado do Departamento Solos, Faculdade de Agronomia, UFRGS. Bolsista do CNPq. E-mail: ibanghi@ufrgs.br

(6) Professor Colaborador Convidado do Departamento de Plantas de Lavoura, Programa de Pós Graduação em Fitotecnia, Faculdade de Agronomia - UFRGS. E-mail: cbredemeier@gmail.com

(7) Aluna de Graduação da Faculdade de Agronomia - UFRGS. Bolsista do PIBIC (CNPq). E-mail: vladirene@gmail.com
} 
da obtenção de elevado rendimento de grãos em semeadura tardia, por não responder à adubação nitrogenada em cobertura.

Termos de indexação: Oryza sativa L., componentes de rendimento, adubação nitrogenada em cobertura.

\title{
SUMMARY: GRAIN YIELD AND EFFICIENCY OF BROADCAST NITROGEN IN FLOODED RICE PLANTED IN DISTINCT PERIODS IN RIO GRANDE DO SUL STATE, BRAZIL
}

\begin{abstract}
The potential grain yield of late flooded rice is important for decision making of producers. Yields of rice crops sown after the recommended period are restricted due to unfavorable climatic conditions. The objective of this research was to evaluate grain yield and agronomic, technical and economic efficiency of broadcast nitrogen for flooded rice sown in December in the state of Rio Grande do Sul, Brazil. The field experiment was carried out in 2005/2006, in Cachoeirinha. Treatments consisted of two sowing dates, recommended (November) and late (December), four seeding rates (50, 100, 150, and $200 \mathrm{~kg} \mathrm{ha}^{-1}$ ) and four nitrogen levels $\left(0,60,120\right.$, and $\left.180 \mathrm{~kg} \mathrm{ha}^{-1}\right)$. The experiment had a randomized block design using split plots with three replications. Rice grain yield and response to nitrogen topdressing were reduced by the late sowing date. The doses for maximum technical and economic efficiency were reduced with the sowing delay, and nitrogen agronomic efficiency was reduced with the sowing delay and $\mathrm{N}$ fertilizer dose. The number of panicles $\mathrm{m}^{-2}$ did not respond to nitrogen broadcast and was one of the most limiting yield components.
\end{abstract}

Index terms: Oryza sativa L., yield components, topdressed nitrogen fertilization.

\section{INTRODUÇÃO}

O arroz ocupa posição de destaque dos pontos de vista econômico e social no Estado do Rio Grande do Sul, onde é cultivado em áreas de várzea, em sistema de irrigação por inundação. A má drenagem natural dessas áreas e o excesso de precipitação pluvial nos meses de preparo do solo e de semeadura (setembronovembro) muitas vezes impedem que o arroz seja semeado na época recomendada pela pesquisa. O período recomendado para semeadura de um cultivar de ciclo médio inicia-se entre $1^{\circ}$ e 11 de outubro na maior parte do Estado, e termina em 20 de novembro em todas as regiões. A época recomendada para semeadura de cultivares de ciclo precoce, inicia-se entre 11 e 21 de outubro, e encerra em 30 de novembro em todas as regiões (SOSBAI, 2007). Portanto, na maior parte do Estado, o período recomendado para a semeadura é de, no máximo, 50 dias, o que requer elevado investimento por parte dos produtores em maquinário e mão-de-obra, visto que a área cultivada anualmente é de mais de um milhão de hectares. Mesmo quando as condições climáticas são favoráveis à semeadura na época recomendada, como na safra 2004/2005, em que os meses de setembro-novembro não foram chuvosos, apenas $78 \%$ da área semeada do Estado foi concluída até o dia 15 de novembro (IRGA, 2006). Assim, mesmo em um ano favorável à semeadura na época recomendada, mais de $20 \%$ da área teve a produtividade comprometida antes mesmo de ser instalada.

A eficiência das práticas agrícolas adotadas em uma lavoura não é resultado apenas da prática em si, mas de uma combinação de fatores, como o momento da aplicação, as condições ambientais e a interação com demais intervenções que possam influenciar o resultado da prática em questão. No caso do arroz, a resposta à adubação nitrogenada é determinada principalmente pela época de semeadura (Stansel, 1975; Slaton et al., 2003; Freitas et al., 2005; Mariot et al., 2005), sendo a sua adequação um dos pontoschave quando se objetiva elevar a produtividade das lavouras. A otimização da eficiência dos nutrientes aplicados é fundamental para atingir alto rendimento de grãos, para diminuir o impacto ambiental e para aumentar a rentabilidade do produtor.

Eficiência nutricional é a relação entre a produção obtida e os nutrientes aplicados, podendo ser expressa de maneiras diferentes (Fageria, 2000). A "eficiência agronômica" significa a produção obtida por unidade de nutriente aplicado. Ainda existem a "eficiência fisiológica", "eficiência agrofisiológica", "eficiência de recuperação" e "eficiência de utilização" (Fageria, 1998). A eficiência nutricional é influenciada pelos vários fatores que afetam a produtividade das culturas, como temperatura, radiação solar, precipitação, características do solo, variabilidade genética, doenças, pragas e plantas daninhas (Fageria, 1998). A maior 
eficiência de uso do N é obtida quando os estádios da microsporogênese (formação do grão de pólen no período entre 21 dias antes e após a floração) e de formação e início de enchimento de grãos ocorrem em períodos de alta radiação solar (Yoshida \& Parao, 1976). No Rio Grande do Sul, o período de maior radiação solar são os meses de dezembro e janeiro, e a coincidência da floração e do início do enchimento de grãos com esses meses é um dos fatores determinantes da recomendação da época de semeadura do arroz.

Além da eficiência nutricional, a eficiência econômica da utilização dos nutrientes também deve ser avaliada. A dose de máxima eficiência econômica pode ser estimada com relativa facilidade quando se conhece a função de produção que descreve a relação entre insumo e produto (Grimm, 1970). Uma vez que a eficiência nutricional do $\mathrm{N}$ diminui com o atraso da semeadura, a eficiência econômica deve diminuir também, e a dose de máxima eficiência econômica deve ser menor.

Outro aspecto desfavorável ao atraso da semeadura é a maior incidência de moléstias, fato que pode ser agravado com a aplicação de altas doses de $\mathrm{N}$ em cobertura (Fageria et al., 1997), o que determina cautela na recomendação da dose de $\mathrm{N}$, devendo-se, geralmente, reduzir a quantidade a ser aplicada. Com isso, há redução no número de perfilhos produzidos por planta e, conseqüentemente, do principal componente do rendimento de grãos, o número de panículas por metro quadrado, limitando o potencial de rendimento de grãos (Mariot et al., 2003).

$\mathrm{O} \mathrm{N}$ é o nutriente que mais comumente limita o rendimento das culturas, por ser exigido em grande quantidade. Devido a sua mobilidade e capacidade de transformação (processos de desnitrificação, volatilização e lixiviação), é facilmente perdido para o ambiente quando há manejo errado da adubação. A sua deficiência diminui a fotossíntese, devido à redução na síntese e na atividade da enzima responsável pela assimilação de $\mathrm{CO}_{2}$, a rubisco (Makino et al., 1984). A deficiência de $\mathrm{N}$ também pode limitar o crescimento e o desenvolvimento das plantas de duas maneiras: pela diminuição da eficiência de conversão de energia, devido à maior partição de assimilados para formação de raízes, e pela redução da quantidade de radiação solar interceptada, em função do menor desenvolvimento foliar (Gastal et al., 1992). Para cada tonelada de grãos de arroz produzida, são extraídos de 15 a $17 \mathrm{~kg}$ de N (Mae, 1997), sendo a variação na eficiência de uso de $\mathrm{N}$ devida, entre outros fatores, a diferenças nas condições ambientais. Com radiação solar e temperatura do ar mais elevadas, a resposta à adubação nitrogenada é maior para as plantas de qualquer um dos três grupos de cultivares (tradicional, moderno e americano) (Scivittaro \& Machado, 2004).

$\mathrm{O}$ correto manejo da adubação nitrogenada em cobertura nas semeaduras da época tardia pode minimizar as perdas que se verificam no potencial de rendimento de grãos e na eficiência de uso do N. Não há dados experimentais que quantifiquem a redução que ocorre na eficiência da adubação nitrogenada. $\mathrm{O}$ objetivo deste trabalho foi comparar o rendimento de grãos e a eficiência agronômica, técnica e econômica do $\mathrm{N}$ aplicado em cobertura e o rendimento de grãos de arroz irrigado nas semeaduras das épocas recomendada e tardia no Estado do Rio Grande do Sul.

\section{MATERIAL E MÉTODOS}

O experimento foi realizado durante a estação de crescimento 2005/06, na Estação Experimental do Arroz (EEA) do Instituto Rio Grandense do Arroz (IRGA), localizada no município de Cachoeirinha, região ecoclimática da Depressão Central do Estado do Rio Grande do Sul, situada a $29^{\circ} 55^{\prime} 30$ " de latitude sul, a $50^{\circ} 58^{\prime} 21$ " de longitude oeste, e altitude de $7 \mathrm{~m}$ (Brasil, 1973).

O solo da área experimental é classificado como Gleissolo háplico Ta distrófico típico (Embrapa, 1999). As amostras de solo coletadas em agosto de 2005 apresentaram os seguintes resultados: teor de argila: $15 \%$; pH (água): 5,3; índice SMP: 6,5; P (extraído por Mehlich-I): 25,6 $\mathrm{mg} \mathrm{dm}^{-3}$; K (extraído por Mehlich-I): $35 \mathrm{mg} \mathrm{dm}{ }^{-3} ; \mathrm{CTC}_{\mathrm{pH}} 7,0: 6,6 \mathrm{cmol}_{\mathrm{c}} \mathrm{dm}^{-3}$ e matéria orgânica: 1,5 \% (Tedesco et al., 1995).

O clima da região é do tipo subtropical úmido, conforme classificação de Köeppen, sendo considerado de transição entre os tipos $\mathrm{Cfa}_{1}$ (isoterma anual inferior a $18{ }^{\circ} \mathrm{C}$ ) e $\mathrm{Cfa}_{2}$ (isoterma anual superior a $18^{\circ} \mathrm{C}$ ). A temperatura mínima média do ar é de $9,8^{\circ} \mathrm{C}$ no mês mais frio (julho) e a máxima é de $31,6{ }^{\circ} \mathrm{C}$ no mês mais quente (janeiro). A precipitação pluvial média anual é de $1.425 \mathrm{~mm}$ e a disponibilidade de radiação solar máxima é de $502 \mathrm{cal} \mathrm{cm}^{-2}$ dia $^{-1}$ no mês de dezembro (IPAGRO, 1989). As temperaturas máximas e mínimas do ar e a radiação solar diária foram registradas nos meses do período experimental.

A área do experimento esteve em pousio no ano agrícola anterior (2004/2005). No inverno de 2005, foi semeado azevém (Lolium multiflorum Lam.) sobre serradela nativa (Ornitophus micranthus (Benth.) Arechavaleta), formando uma cobertura de 2,4 $\mathrm{t} \mathrm{ha}^{-1}$ de matéria seca sobre o solo por ocasião da semeadura do arroz. Realizou-se a drenagem da área em setembro, pela abertura de pequenos sulcos, em função da dificuldade de drenagem natural, devido à sistematização em nível da área.

O experimento constou de duas épocas de semeadura, sendo a primeira no dia 2 de novembro de 2005 , considerada preferencial para a região, e a segunda, no dia 9 de dezembro de 2005 , considerada tardia. Em cada época, foram testadas quatro doses de $\mathrm{N}$ em cobertura $\left(0,60,120\right.$ e $\left.180 \mathrm{~kg} \mathrm{ha}^{-1}\right)$, combinadas com quatro densidades de semeadura (50, 100,150 e $200 \mathrm{~kg} \mathrm{ha}^{-1}$ de sementes). O delineamento 
experimental utilizado foi de blocos casualizados, dispostos em parcelas subdivididas, com três repetições. As épocas de semeadura foram locadas nas parcelas principais e as combinações entre densidade de semeadura e nível de $\mathrm{N}$ nas subparcelas. Cada subparcela foi composta por 10 linhas espaçadas em $0,17 \mathrm{~m}$, com $10 \mathrm{~m}$ de comprimento, totalizando $17 \mathrm{~m}^{2}$, com área útil de 13,6 $\mathrm{m}^{2}$ (as duas linhas de bordaduras não foram utilizadas nas avaliações). Cada parcela principal continha 48 subparcelas, totalizando uma área de $816 \mathrm{~m}^{2}$.

O cultivar utilizado foi a IRGA 420, de ciclo médio. A adubação de base foi aplicada em linha, no momento da semeadura, para expectativa de rendimento de grãos superior a $9 \mathrm{t} \mathrm{ha}^{-1}$ (SOSBAI, 2007). Em todos os tratamentos, foi aplicada a adubação de $350 \mathrm{~kg} \mathrm{ha}^{-1}$ da fórmula NPK 5-20-30, equivalendo a $17,5 \mathrm{~kg}^{\text {ha-1 }}$ de $\mathrm{N}, 70 \mathrm{~kg} \mathrm{ha}^{-1}$ de $\mathrm{P}_{2} \mathrm{O}_{5}$ e $105 \mathrm{~kg} \mathrm{ha}^{-1}$ de $\mathrm{K}_{2} \mathrm{O}$. As sementes foram previamente tratadas com o inseticida fipronil (40 g i.a. $100 \mathrm{~kg}$ de sementes $\left.{ }^{-1}\right)$ para controle preventivo da bicheira-da-raiz (Oryzophagus oryzae), e com fungicida à base de thiram e de carboxina $\left(94\right.$ g i.a. $100 \mathrm{~kg}$ de sementes $\left.{ }^{-1}\right)$. A semeadura foi realizada em solo seco, de forma mecanizada, com uma semeadora de parcelas.

A adubação nitrogenada em cobertura foi feita manualmente, a lanço, em dia com temperatura amena e sem ventos fortes, utilizando como fonte a uréia ( $45 \%$ de $\mathrm{N})$. A aplicação das três doses de $\mathrm{N}$ em cobertura $\left(60,120\right.$ e $\left.180 \mathrm{~kg} \mathrm{ha}^{-1}\right)$ foi parcelada em duas épocas: $70 \%$ da dose no estádio $\mathrm{V}_{3}$, e $30 \%$ no estádio $\mathrm{V}_{8}$, conforme a escala proposta por Counce et al. (2000). A irrigação por inundação teve início imediatamente após a realização da primeira adubação nitrogenada em cobertura, com manutenção constante de uma lâmina de água de 5 a $10 \mathrm{~cm}$ de altura sobre o solo em todos os tratamentos. A supressão da entrada de água ocorreu quando as plantas estavam no estádio $R_{7}$, em que ao menos um grão da panícula do colmo principal apresentava a casca amarela. $\mathrm{O}$ controle de plantas daninhas foi realizado pela aplicação de herbicidas recomendados para a cultura em pós-emergência (SOSBAI, 2007).

As variáveis avaliadas no experimento foram: acúmulo de $\mathrm{N}$ na parte aérea no estádio de emborrachamento $\left(R_{2}\right)$, rendimento de grãos, número de panículas por metro quadrado e rendimento de matéria seca (MS) da parte aérea na colheita. No estádio de emborrachamento, foram coletadas duas amostras de $1 \mathrm{~m}$ linear em cada subparcela, totalizando $0,34 \mathrm{~m}^{2}$, que foram secas em estufa a $60^{\circ} \mathrm{C}$ até atingir peso constante para determinação da MS e extrapolação para 1 ha. Em seguida, a amostra foi moída e o teor de $\mathrm{N}$ no tecido foi determinado seguindo a metodologia proposta por Tedesco et al. (1995). O teor de $\mathrm{N}$ na planta foi multiplicado pela quantidade de MS de 1 ha para obtenção do acúmulo de $\mathrm{N}$ na parte aérea da planta no estádio de emborrachamento. O rendimento de grãos foi obtido pela extrapolação da produção obtida numa área de $11,5 \mathrm{~m}^{2}$, dentro da área útil da subparcela, para 1 ha, corrigindo-se a umidade para $130 \mathrm{~g} \mathrm{~kg}^{-1}$. No momento da colheita, foram colhidas separadamente as plantas de duas amostras de $1 \mathrm{~m}$ linear, e contado o número de panículas, que foi dividido pela área coletada para obtenção do número de panículas por área. Essa mesma amostra serviu para a avaliação de MS da parte aérea na colheita, após secagem em estufa a $60{ }^{\circ} \mathrm{C}$, até atingir peso constante.

A dose de máxima eficiência técnica (DMET) foi calculada a partir da equação do rendimento de grãos em função da dose de $\mathrm{N}$ aplicada em cobertura, igualando-se a derivada da função a zero. A dose de máxima eficiência econômica (DMEE) foi calculada pela fórmula proposta por Grimm (1970), que deriva da equação do lucro líquido por hectare:

$$
\mathrm{L}=\mathrm{V} \mathrm{Y}-\mathrm{F}_{\mathrm{o}}-\mathrm{F}_{1} \mathrm{X}
$$

em que L é o lucro líquido, $\mathrm{V}$ é o preço de venda do arroz, Y é a equação do rendimento de grãos em função da dose de $\mathrm{N}, \mathrm{F}_{\mathrm{o}}$ é o valor dos custos fixos, e $\mathrm{F}_{1} \mathrm{X}$ é o preço de custo do fertilizante.

Substituindo-se o Y pela equação de rendimento de grãos em função da dose de $\mathrm{N}$ em cobertura, obtémse:

$$
\mathrm{L}=\mathrm{V}(\mathrm{aX}+\mathrm{bX}+\mathrm{c})-\mathrm{F}_{\mathrm{o}}-\mathrm{F}_{1} \mathrm{X}
$$

Para maximizar o lucro, basta derivar a equação e igualá-la a zero, obtendo-se então

$$
\mathrm{X}=-\mathrm{b} / 2 \mathrm{a}+\mathrm{F}_{1} / 2 \mathrm{aV}
$$

Além disso, foi calculada a eficiência agronômica do N (EAN) aplicado pela equação proposta por Baligar et al. (1990):

$$
\mathrm{EAN}=(\mathrm{RF}-\mathrm{RNF}) / \mathrm{QNA}
$$

em que RF é o rendimento de grãos das plantas fertilizadas (kg ha-1), RNF é o rendimento de grãos de plantas não fertilizadas $\left(\mathrm{kg} \mathrm{ha}^{-1}\right)$ e QNA é a quantidade de nutriente aplicada em cobertura $\left(\mathrm{kg} \mathrm{ha}^{-1}\right)$.

$\mathrm{O}$ teor de $\mathrm{N}$ total $\left(\mathrm{mg} \mathrm{L}^{-1}\right)$ da água utilizada para irrigação foi monitorado durante o período experimental, medido quinzenalmente nos pontos de entrada da água e drenagem, para verificar possível beneficiamento do $\mathrm{N}$ disponível por parte das plantas.

Os dados das quatro primeiras variáveis foram submetidos à análise de variância pelo teste $\mathrm{F}$, utilizando-se o programa de processamento de dados SAS. Quando houve significância estatística para os efeitos simples de densidade de semeadura e dose de $\mathrm{N}$ aplicado e para as interações desses fatores com época de semeadura, realizou-se a análise de regressão. Para a variável rendimento de grãos, derivou-se a equação de regressão para encontrar a dose de $\mathrm{N}$ que proporcionaria o maior rendimento de grãos, ou seja, a dose de máxima eficiência técnica. Quando foi 
significativo o efeito simples de época de semeadura, utilizou-se o teste de Tukey para comparação de médias a $5 \%$.

Os resultados da EAN foram submetidos à análise separada dos demais, por constarem de apenas três comparações (rendimentos de grãos dos tratamentos que receberam 60, 120 e $180 \mathrm{~kg} \mathrm{ha}^{-1}$ de N em cobertura comparados ao tratamento sem aplicação de N). Foi realizada a análise de variância dos dados. Quando houve significância estatística, foi feita a comparação de médias pelo teste de Tukey, a $5 \%$.

\section{RESULTADOS E DISCUSSÃO}

Para todas as características avaliadas a interação da dose de $\mathrm{N}$ e época de semeadura foi significativa. Não houve efeito da densidade de semeadura nas variáveis estudadas.

Na época de semeadura preferencial, a quantidade de $\mathrm{N}$ acumulada na parte aérea da planta no emborrachamento aumentou linearmente com incremento da dose de N (Figura 1). Para cada $10 \mathrm{~kg} \mathrm{ha}^{-1}$ de N aplicado em cobertura, houve acúmulo de $14 \mathrm{~kg} \mathrm{ha}^{-1}$ de N na parte aérea das plantas. Na época de semeadura tardia, o acúmulo de $\mathrm{N}$ na parte aérea da planta aumentou de forma quadrática. A quantidade de $\mathrm{N}$ acumulada na época de semeadura preferencial foi superior à da época tardia nos tratamentos onde foi aplicado $\mathrm{N}$ em cobertura. Já no tratamento sem aplicação de $\mathrm{N}$ em cobertura ocorreu o inverso, ou seja, essa variável foi maior na época tardia (Figura 1).

O rendimento de MS da parte aérea na colheita aumentou de forma quadrática com o incremento da dose de $\mathrm{N}$ aplicada em cobertura nas duas épocas de semeadura (Figura 2). Na época de semeadura preferencial, houve acréscimo de matéria seca até a dose de $144,7 \mathrm{~kg} \mathrm{ha}^{-1}$ de $\mathrm{N}$ (dose para a produção máxima), enquanto na época tardia o aumento observado até a dose de $92,7 \mathrm{~kg} \mathrm{ha}^{-1}$. No tratamento sem aplicação de $\mathrm{N}$ em cobertura, o rendimento de MS na época de semeadura tardia foi superior ao da época preferencial. Este comportamento foi semelhante à resposta do rendimento de grãos à aplicação de $\mathrm{N}$ em cobertura (Figura 4).

$\mathrm{Na}$ época de semeadura preferencial, o número de panículas $\mathrm{m}^{-2}$ aumentou linearmente com incremento da dose de $\mathrm{N}$ aplicada, de 549 panículas $\mathrm{m}^{-2}$ (tratamento sem aplicação de N) para 771 panículas $\mathrm{m}^{-2}$ (tratamento com $180 \mathrm{~kg} \mathrm{ha}^{-1} \mathrm{de} \mathrm{N}$ ) (Figura 3). Já na época tardia, esse componente não foi influenciado pela adubação nitrogenada em cobertura, mantendose próximo a 600 panículas $\mathrm{m}^{-2}$.

O rendimento de grãos respondeu de forma quadrática ao incremento da dose de $\mathrm{N}$ nas duas épocas de semeadura (Figura 4). A derivada da equa-

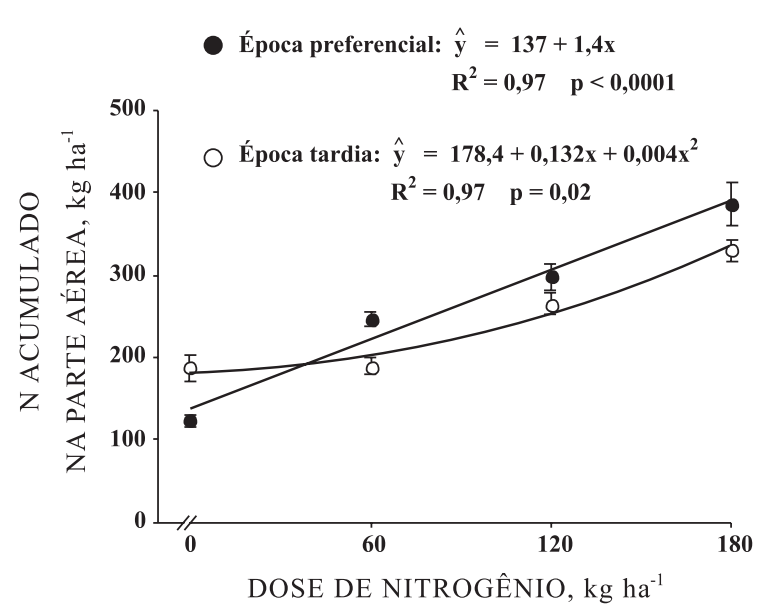

Figura 1. Quantidade de nitrogênio acumulada na parte aérea de planta de arroz irrigado em estádio de emborrachamento para épocas de semeadura preferencial (novembro) e tardia (dezembro), em função da dose de nitrogênio aplicada em cobertura, na média de quatro densidades de semeadura. Barras verticais representam o erro-padrão da média.

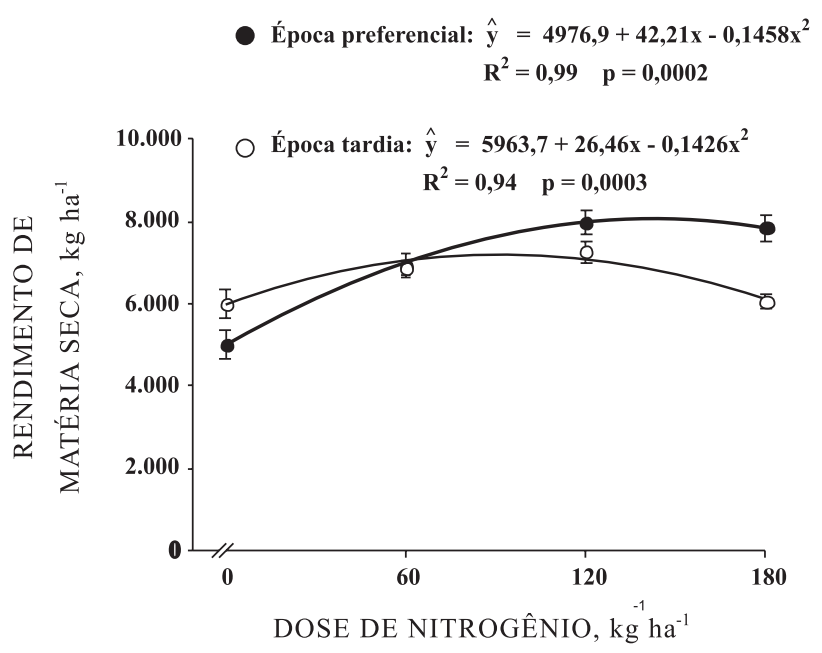

Figura 2. Rendimento de matéria seca da parte aérea de planta de arroz irrigado em estádio de colheita para épocas de semeadura preferencial (novembro) e tardia (dezembro), em função de dose de nitrogênio aplicado em cobertura, na média de quatro densidades de semeadura. Barras verticais representam o erro-padrão da média.

ção de regressão indicou que a dose de máxima eficiência técnica (DMET) foi de $132 \mathrm{~kg} \mathrm{ha}^{-1}$ para obtenção do rendimento de $8.900 \mathrm{~kg} \mathrm{ha}^{-1}$ de grãos. Na época de semeadura tardia, a DMET foi de $83 \mathrm{~kg} \mathrm{ha}^{-1}$, $37 \%$ menor que a obtida na época preferencial para obtenção do rendimento de grãos máximo de $7.670 \mathrm{~kg} \mathrm{ha}^{-1}$.Na época preferencial de semeadura, a adubação nitrogenada em cobertura elevou o rendimento 


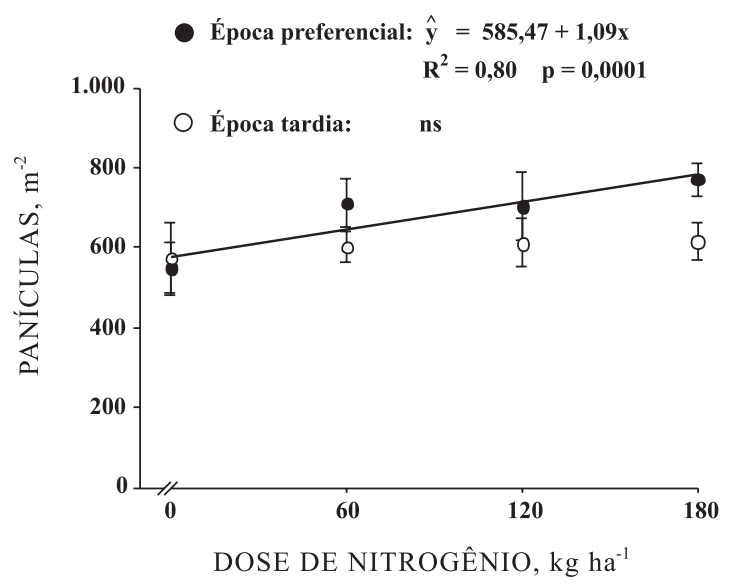

Figura 3. Número de panículas por metro quadrado de arroz irrigado para épocas de semeadura preferencial (novembro) e tardia (dezembro), em função de dose de nitrogênio aplicado em cobertura, na média de quatro densidades de semeadura. Barras verticais representam o erropadrão da média.

de grãos de menos de $6.000 \mathrm{~kg} \mathrm{ha}^{-1}$, no tratamento não fertilizado, até aproximadamente $8.900 \mathrm{~kg} \mathrm{ha}^{-1}$, ao passo que, na época tardia, o incremento no rendimento de grãos com a aplicação de $\mathrm{N}$ em cobertura foi inferior a $1.000 \mathrm{~kg} \mathrm{ha}^{-1}$. No tratamento sem N, o rendimento de grãos da época de semeadura tardia foi superior ao da época de semeadura preferencial (Figura 4), assim como foi verificado para a quantidade de N acumulada na parte aérea, no emborrachamento (Figura 1), e para MS da parte aérea na colheita (Figura 2).

Para o cálculo das DMEE de cada época de semeadura, foram considerados os coeficientes "a" e "b" das equações de regressão obtidas em cada época de semeadura, o valor de venda (V) do arroz tipo 1 Longo Fino de $\mathrm{R} \$ 0,387 \mathrm{~kg}^{-1}$ (Agrolink, 2007) e do N $\left(\mathrm{F}_{1}\right)$ de $\mathrm{R} \$ 1,739 \mathrm{~kg}^{-1}\left(\mathrm{R} \$ 800,00 \mathrm{t}^{-1}\right.$ de uréia com $45 \%$ de N) (Agrolink, 2007). A DMEE da época preferencial de semeadura foi de $120 \mathrm{~kg} \mathrm{ha}^{-1}$ de N, ou seja, $90 \%$ do valor da DMET. Este valor está de acordo com o encontrado por diversos autores (Schlindwein, 2003; Halvin et al., 2005), que citam que a DMEE costuma ser de 80 a $95 \%$ da DMET. Já na época de semeadura tardia, a DMEE foi de $55 \mathrm{~kg} \mathrm{ha}^{-1}$ de N, apenas $66 \%$ da DMET, abaixo do considerado normal pelos autores. Utilizando-se estes valores na função de produção com os mesmos valores de venda do arroz e de custo do N, as produtividades que trariam o maior retorno econômico do $\mathrm{N}$ seriam de $8.870 \mathrm{~kg} \mathrm{ha}^{-1}$ na época de semeadura preferencial e $7.606 \mathrm{~kg} \mathrm{ha}^{-1}$ na época de semeadura tardia.

Em relação à eficiência agronômica do $\mathrm{N}$ (EAN) aplicado, foi significativa a interação de época de semeadura e dose de $\mathrm{N}$ aplicada em cobertura. A EAN caiu com o incremento da dose de $\mathrm{N}$ e com o atraso da época de semeadura, sendo maior na época de semeadura preferencial em relação à tardia, independentemente da dose de N (Figura 5). Esta diminuição da EAN evidencia que parte do $\mathrm{N}$ aplicado não foi destinado à produção de grãos, ou seja, foi perdido para o ambiente ou ficou em excesso no tecido vegetal, o que predispõe a planta ao desenvolvimento de doenças, quando há condições favoráveis, e ao acamamento de plantas.

$\mathrm{Na}$ época de semeadura preferencial, a EAN foi reduzida em $59 \%$ quando a dose aplicada aumentou de 60 para $180 \mathrm{~kg} \mathrm{ha}^{-1}$ de N. Na época tardia, as reduções da EAN em relação à época preferencial foram de 70 e $85 \%$, respectivamente, com as doses de 60 e $120 \mathrm{~kg} \mathrm{ha}^{-1}$. Com a aplicação da maior dose $\left(180 \mathrm{~kg} \mathrm{ha}^{-1}\right)$, a EAN atingiu valor próximo a zero na época tardia (Figura 5). Essa diminuição ocorreu porque o rendimento de grãos não aumentou na mesma proporção que a dose de $\mathrm{N}$ aplicada, pois o aumento da produtividade depende de outros fatores, que não foram fornecidos em doses crescentes como o $\mathrm{N}$, como o suprimento de fotoassimilados. O incremento da dose de N, além da reduzir a eficiência de absorção, diminui também a eficiência de uso do $\mathrm{N}$ já absorvido pela planta (Mariot et al., 2003).

O menor rendimento de grãos obtido na época de semeadura tardia em relação à preferencial, nos tratamentos com aplicação de $\mathrm{N}$ em cobertura, está de acordo com os resultados encontrados por diversos autores (Slaton et al., 2003; Mariot et al., 2003; Freitas et al., 2005). Esse resultado geralmente é atribuído ao aumento da esterilidade de espiguetas, devido à ocorrência de temperaturas baixas, principalmente no período de microsporogênese, e à menor disponibilidade de radiação solar próximo à antese (Stansel, 1975;

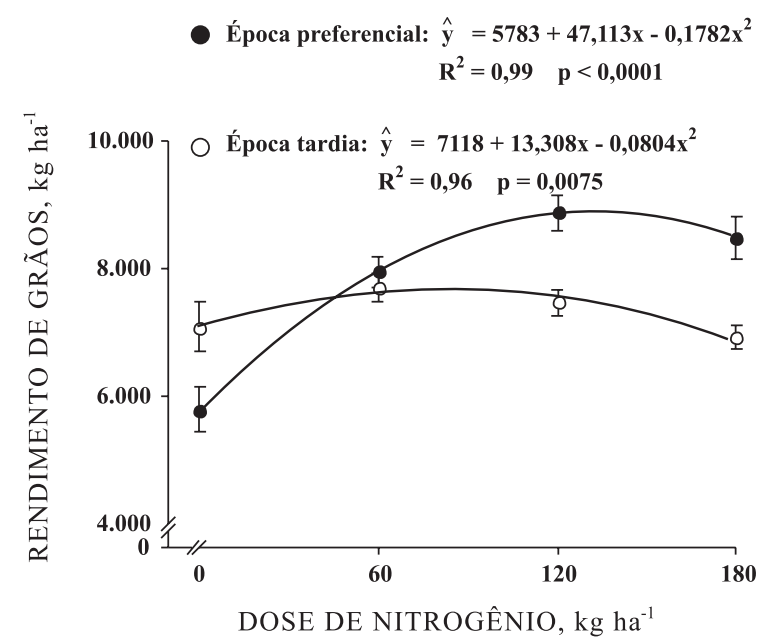

Figura 4. Rendimento de grãos de arroz irrigado para épocas de semeadura preferencial (novembro) e tardia (dezembro), em função da dose de nitrogênio aplicada em cobertura, na média de quatro densidades de semeadura. Barras verticais representam o erro-padrão da média. 


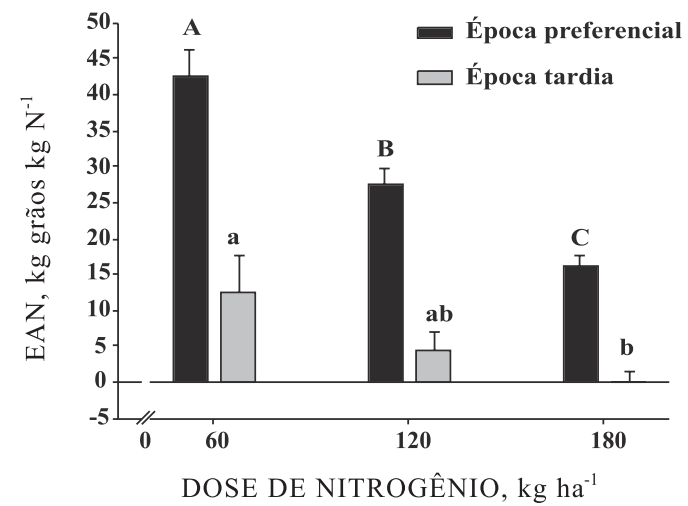

Figura 5. Eficiência agronômica do nitrogênio (EAN) aplicado em cobertura para épocas de semeadura preferencial (novembro) e tardia (dezembro), em função da dose de nitrogênio aplicada em cobertura, na média de quatro densidades de semeadura. Letras maiúsculas representam comparação de médias na época de semeadura preferencial e minúsculas na época de semeadura tardia. Barras verticais representam o erro-padrão.

Terres \& Gali, 1985; Lima et al., 2005). Na época de semeadura preferencial, o número de panículas $\mathrm{m}^{-2}$ aumentou de forma linear com o incremento da dose de $\mathrm{N}$ em cobertura (Figura 3), enquanto, na época de semeadura tardia, esta variável não respondeu ao aumento da dose de $\mathrm{N}$ aplicada em cobertura, situandose em torno de 600 panículas $\mathrm{m}^{-2}$. A ausência de resposta do número de panículas $\mathrm{m}^{-2}$ à adubação nitrogenada na época tardia certamente limitou a elevação do rendimento de grãos, já que é o componente mais associado ao rendimento de grãos de arroz irrigado (Mariot et al., 2003).

Um dos fatores que modulam a absorção do $\mathrm{N}$ é a disponibilidade de energia, pois o transporte de nitrato para dentro das células é um processo ativo, dependente do bombeamento de prótons $\mathrm{H}^{+}$para fora da célula pela bomba de prótons $\mathrm{H}+$-ATPase (Bredemeier \& Mundstock, 2000). A absorção de nitrato $\left(\mathrm{NO}_{3}{ }^{-}\right)$também pode ocorrer contra um potencial eletroquímico, por meio de um sistema simporte, com transporte simultâneo de $\mathrm{H}^{+}$e nitrato para dentro das células. A relação de $2 \mathrm{H}^{+}: 1 \mathrm{NO}_{3}{ }^{-}$ é observada para a absorção no sistema de membranas, sendo o custo energético para esta absorção de $2 \mathrm{~mol}$ de ATP para cada 1 mol de nitrato "capturado" pelas plantas (Fernandes \& Rossiello, 1995). Depois de absorvido, o nitrato, para ser assimilado, deve ser reduzido a nitrito pela enzima nitrato redutase, que tem sua atividade regulada pela intensidade luminosa e pelo nível de carboidratos disponível (Sivasankar \& Oaks, 1996). Com menor quantidade de $\mathrm{N}$ acumulada nos tecidos, a produção de fotoassimilados pela planta é menor, pois o N é um dos principais componentes da clorofila, pigmento que absorve energia solar e desencadeia o processo de fotossíntese pelas plantas (Taiz \& Zeiger, 2004). Assim, as menores absorção e assimilação de $\mathrm{N}$ na época de semeadura tardia em relação à preferencial limitaram o desenvolvimento da planta e podem ter diminuído também a interceptação de radiação solar para a produção de fotoassimilados.

$\mathrm{O}$ maior rendimento de grãos, quantidade de $\mathrm{N}$ acumulada no tecido, rendimento de massa seca na colheita e número de panículas $\mathrm{m}^{-2}$ no tratamento sem aplicação de $\mathrm{N}$ em cobertura na época de semeadura tardia em relação à preferencial podem ser decorrentes de duas possibilidades. A primeira é de que houve maior absorção de $\mathrm{N}$ pelas plantas no tratamento testemunha (sem aplicação de $\mathrm{N}$ em cobertura), na época tardia em relação à época preferencial, por se beneficiarem de condições climáticas mais favoráveis no início do desenvolvimento da planta. O principal mecanismo de contato íon-raiz para o $\mathrm{N}$ é o fluxo de massa, regulado pela transpiração da planta, que é uma função da taxa de movimento para a raiz e da concentração de nutrientes dissolvidos no solo (Fitter \& Hay, 1992; Marschner, 1995; Jackson \& Caldwell, 1996). A evaporação de água das paredes celulares do mesófilo foliar gera grandes pressões negativas (ou tensões) na água apoplástica. Essas pressões negativas são transmitidas ao xilema e fazem a água subir por meio dos condutos do xilema (Taiz \& Zeiger, 2004). A maior temperatura do ar no mês de dezembro em relação à novembro (Quadro 1) provoca maior transpiração das plantas da época tardia e, consequentemente, maior contato do $\mathrm{N}$ do solo com a raiz, em comparação com as plantas da época preferencial. Além da temperatura do ar, nos meses de dezembro e janeiro há maior incidência de radiação solar global, o que pode ter aumentado a eficiência e a assimilação do $\mathrm{N}$ absorvido na época tardia de semeadura.

Quadro 1. Temperaturas $\left({ }^{\circ} \mathrm{C}\right)$ máxima e mínima do ar e radiação solar diária $\left(\mathrm{Cal} \mathrm{cm}^{-2}\right)$ médias mensais ocorridas durante o periodo experimental na EEA/IRGA. Cachoeirinha, RS. 2005/2006

\begin{tabular}{|c|c|c|c|}
\hline \multirow{2}{*}{$\mathbf{M}^{\hat{e ̂ s}}$} & \multicolumn{2}{|c|}{ Temperatura } & \multirow{2}{*}{ Radiação solar } \\
\hline & Máxima & Mínima & \\
\hline & ${ }^{\circ} \mathrm{C}$ & - & $\mathrm{Cal} \mathrm{cm}^{-2}$ \\
\hline Novembro & 28,8 & 15,4 & 484,4 \\
\hline Dezembro & 29,6 & 15,9 & 513,2 \\
\hline Janeiro & 32,3 & 20,1 & 462 \\
\hline Fevereiro & 30,2 & 18,4 & 445 \\
\hline Março & 30,1 & 18,2 & 428 \\
\hline Abril & 26,3 & 13,9 & 360 \\
\hline
\end{tabular}


Outra possibilidade é que as plantas da época tardia tenham sido favorecidas pela forte estiagem que ocorreu durante a estação de crescimento. O nível do rio Gravataí, do qual foi captada a água para irrigação do experimento, diminuiu e elevou o teor de $\mathrm{N}$ total da água (Quadro 2) especialmente nos meses de dezembro, janeiro e fevereiro. Este fato pode ter interferido nos efeitos da adubação nitrogenada, especialmente nos tratamentos sem aplicação de N em cobertura, nas duas épocas de semeadura. Em dezembro, as plantas da época preferencial (novembro) ainda estavam no período vegetativo, e as análises da água nos pontos de captação e de drenagem da estação experimental mostraram que, durante todo o período experimental, a água que saía da lavoura possuía menor teor de $\mathrm{N}$ total (Quadro 1), e as plantas poderiam se beneficiar do $\mathrm{N}$ da água. Cabe ressaltar que, em outros experimentos em que se compararam épocas de semeadura, também em ano de estiagem, os tratamentos sem aplicação de $\mathrm{N}$ em cobertura também apresentaram rendimentos superiores aos da época preferencial de semeadura (Freitas et al., 2005).

Quadro 2. Teor de $\mathrm{N}$ total $\left(\mathrm{mg} \mathrm{L}^{-1}\right)$ nos locais de captação e drenagem da água utilizada para irrigação no experimento. Cachoeirinha, RS. 2005/2006

\begin{tabular}{crc}
\hline Data & Captação & Drenagem \\
& \multicolumn{2}{c}{ Teor de N $\left(\mathrm{mg} \mathrm{L}^{-1}\right)$} \\
$14 / 11 / 05$ & 3,38 & 1,13 \\
$21 / 11 / 05$ & 5,64 & 0,38 \\
$28 / 11 / 05$ & 9,40 & 1,50 \\
$05 / 12 / 05$ & 14,29 & 1,50 \\
$12 / 12 / 05$ & 21,43 & 0,75 \\
$19 / 12 / 05$ & 17,67 & 0,38 \\
$26 / 12 / 05$ & 31,90 & 2,54 \\
$02 / 01 / 05$ & 19,55 & 0,00 \\
$09 / 01 / 05$ & 17,30 & 0,75 \\
$26 / 01 / 05$ & 22,94 & 0,00 \\
$23 / 01 / 05$ & 9,40 & 0,75 \\
$30 / 01 / 05$ & 7,40 & 1,13 \\
$06 / 02 / 05$ & 14,29 & 0,38 \\
$11 / 02 / 05$ & 16,30 & 0,00 \\
$20 / 02 / 05$ & 13,16 & 3,01 \\
$01 / 03 / 06$ & 4,51 & 0,75 \\
$06 / 03 / 06$ & 7,14 & 0,38 \\
$13 / 03 / 06$ & 15,04 & 2,63 \\
$20 / 03 / 06$ & 7,52 & 0,00 \\
$27 / 03 / 06$ & 13,91 & 1,88 \\
\hline & & \\
\hline
\end{tabular}

\section{CONCLUSÕES}

1. O rendimento de grãos e a resposta à adubação nitrogenada em cobertura foram menores na época tardia em relação à preferencial.
2. A eficiência agronômica do $\mathrm{N}$ aplicado em cobertura diminuiu com o incremento da dose e principalmente com o atraso da época de semeadura, limitando o desenvolvimento da planta e o rendimento de grãos.

3. O número de panículas foi um dos principais componentes de rendimento limitante à obtenção de elevado rendimento de grãos em semeadura tardia, por não responder à adubação nitrogenada em cobertura.

4. A dose de máxima eficiência econômica diminuiu com o atraso da época de semeadura.

\section{LITERATURA CITADA}

AGROLINK. Cotações de produtos agrícolas: Consulta ao preço pago ao produtor pelo arroz tipo 1 longo fino no RS. Disponível em <http://www.agrolink.com.br/cotacoes/ index.asp>. Acesso em: 15 jan 2007.

BALIGAR, V.C.; DUNCAN, R.R. \& FAGERIA, N.K. Soil-plant interaction on nutrient efficiency in plants: An overview. In: BALIGAR, V.C. \& DUNCAN, R.R., eds. Crops as enhancers of nutrient use. San Diego, Academic, 1990. p.351-373.

BRASIL. Ministério da Agricultura. Levantamento de reconhecimento dos solos do estado do Rio Grande do Sul. Recife, Convênio MA/DPP - SA/ DRNR, 1973. 431p. (Boletim Técnico, 30).

BREDEMEIER, C. \& MUNDSTOCK, C.M. Regulação da absorção e assimilação do nitrogênio nas plantas. Ci. Rural, 30:365-372, 2000

COUNCE, P.A.; KEISLING, T.C. \& MITCHELL, A.J. A uniform, objective, and adaptative system for expressing rice development. Crop Sci., 40:436-443, 2000.

EMPRESA BRASILEIRA DE PESQUISA AGROPECUÁRIA EMBRAPA. Centro Nacional de Pesquisa de Solos. Sistema brasileiro de classificação de solos. Rio de Janeiro, Embrapa Solos, 1999. 412p.

FAGERIA, N.K.; BALIGAR, V.C. \& JONES, C.A. Growth and mineral nutrition of field crops. 2.ed. New York, M. Dekker, 1997. 624p.

FAGERIA, N.K. Otimização da eficiência nutricional na produção das culturas. R. Bras. Eng. Agríc. Amb., 2:6-16, 1998.

FAGERIA, N.K. Eficiência do uso de potássio pelos genótipos de arroz de terras altas. Pesq. Agropec. Bras., 35:21152120,2000 .

FERNANDES, M.S. \& ROSSIELO, R.O.P. Mineral nitrogen in plant physiology and plant nutrition. Crit. Rev. Plant Sci., 14:111-118, 1995.

FITTER, A.H. \& HAY, R.K.M. Mineral nutrients In: FITTER, A.H. \& HAY, R.K.M. Environmental physiology of plants. London, Academic, 1992. p.66-120. 
FREITAS, T.F.S.; MARIOT, C.H.P.; MENEZES, V.G.; RAMIREZ, H.V.; LIMA, A.L. \& SILVA, P.R.F. Rendimento de grãos de arroz irrigado em função de níveis de manejo nas épocas de semeadura preferencial e tardia. In: CONGRESSO BRASILEIRO DE ARROZ IRRIGADO, 4.; REUNIÃO DA CULTURA DO ARROZ IRRIGADO, 26. Santa Maria, 2005. Anais. Santa Maria, Orium, 2005. v.1. p.344-346.

GASTAL, F.; BELANGER, G. \& LEMAIRE, G. A model of the leaf extension rate of tall fescue in response to nitrogen and temperature. Ann. Bot., 70:437-442, 1992.

GRIMM, S.S. Aspectos econômicos da adubação. Porto Alegre, Universidade Federal do Rio Grande do Sul, 1970. 14p. (Boletim Técnico, 6)

INSTITUTO DE PESQUISAS AGRONÔMICAS - IPAGRO. Atlas Agroclimático do estado do Rio Grande do Sul. Secretaria da Agricultura, Departamento de Pesquisa, Seção de Ecologia Agrícola. Porto Alegre, 1989. 3v.

HAVLIN, J.L.; BEATON, J.D.; TISDALE, S.L. \& NELSON, W.L. Soil fertility and fertilizers: an introduction to nutrient management. 7ed. New Jersey, Pearsonprentice hall, 2005. Cap. 7, p.219.

INSTITUTO RIO GRANDENSE DO ARROZ - IRGA, 2006. Censo da lavoura de arroz irrigado do Rio Grande do Sul - safra 2004/2005. Porto Alegre, 2006. 122p.

JACKSON, R.B. \& CALDWELL, M.M. Integrating resource heterogeneity and plant plasticity: Modeling nitrate and phosphate uptake in a patchy soil environment. J. Ecol., 84:891-903, 1996.

LIMA, A.L.; MENEZES, V.G.; MARIOT, C.H.P. \& RAMIREZ, H.R. Esterilidade de espiguetas de arroz irrigado em função da época de semeadura - safra 2004-/05. In: CONGRESSO BRASILEIRO DE ARROZ IRRIGADO, 4.; REUNIÃO DA CULTURA DO ARROZ IRRIGADO, 26., Santa Maria, 2005. Anais. Santa Maria, Orium, 2005. v.1. p.238-240.

MAE, T. Physiological nitrogen efficiency in rice: Nitrogen utilization, photosyntesis, and yield potential. Plant Soil, 196:201-210, 1997.

MAKINO, A.; MAE, T. \& OHIRA, K. Relation between nitrogen and ribulose 1,5-bibhosphate carboxylase in rice leaves from emergence through senescence. Plant Cell Physiol., 25:429-437, 1984.

MARIOT, C.H.P.; SILVA, P.R.F.; MENEZES, V.G. \& TEICHMANN, L.L. Resposta de duas cultivares de arroz irrigado à densidade de semeadura e à adubação nitrogenada. Pesq. Agropec. Bras., 38:233-241, 2003.
MARIOT, C.H.P.; MENEZES, V.G.; LIMA, A.L.; RAMIREZ, H.V. \& NEVES, G. Influência da época de semeadura no rendimento de grãos de cultivares de arroz irrigado safras 2003/04 e 2004/05. In: CONGRESSO BRASILEIRO DE ARROZ IRRIGADO, 4.; REUNIÃO DA CULTURA DO ARROZ IRRIGADO, 26., Santa Maria, 2005. Anais. Santa Maria, Orium, 2005. v.1. p.251-253.

MARSCHNER, H. Mineral nutrition of higher plants. London, Academic Press, 1995. 889p.

SCIVITTARO, W.B. \& MACHADO, M.O. Adubação e calagem para a cultura do arroz irrigado. In: Arroz Irrigado no Sul do Brasil. Brasília, Embrapa Informação Tecnológica, 2004. p. 259-297.

SCHLINDWEIN, J.A. Calibração de métodos de determinação e estimativa de doses de fósforo e potássio em solos sob o sistema plantio direto. Porto Alegre, Universidade Federal do Rio Grande do Sul, 2003. 169p. (Tese de Doutorado)

SIVASANKAR, S. \& OAKS, A. Nitrate assimilation in higher plants - the effect of metabolites and light. Plant Physiol. Biochem., 34:609-620, 1996.

SLATON, N.A.; LINSCOMBE, S.D.; NORMAN, R.J. \& GBUR, E.E. Seeding date effect on rice grain yields in Arkansas and Louisiana. Agron. J., 95:218-223, 2003.

SOCIEDADE SUL-BRASILEIRA DE ARROZ IRRIGADO SOSBAI. Arroz irrigado: Recomendações técnicas da pesquisa para o Sul do Brasil. In: CONGRESSO BRASILEIRO DE ARROZ IRRIGADO, 5.; REUNIÃO DA CULTURA DO ARROZ IRRIGADO, 28., Pelotas, 2007. Anais. Pelotas, 2007. 164p.

STANSEL, J.W. Effective utilization of sunlight. In: STANSEL, J.W. \& MILLER, J.E. Six decades of rice research in Texas. College Station, Texas Agricultural Experiment Station, 1975. p.43-50. (Research Monograph, 4)

TAIZ, L. \& ZEIGER, E. Fisiologia vegetal. 3.ed. Porto Alegre, Artmed, 2004. 719p.

TERRES, A.L. \& GALLI, J. Efeitos do frio em cultivares de arroz irrigado no Rio Grande do Sul. In: CENTRO DE PESQUISA AGROPECUÁRIA E TERRAS BAIXAS (Pelotas, RS) Fundamentos para a cultura do arroz irrigado. Campinas, Fundação Cargill, 1985. p.83-94.

TEDESCO, M.J.; VOLKWEISS, S.J. \& BOHNEN, H. Análise de solo, planta e outros materiais. 2.ed. Porto Alegre, Universidade Federal do Rio Grande do Sul, 1995. 174p.

YOSHIDA, S. \& PARAO, F.T. Climatic influence on yield and yield components of lawland rice in the tropics. Climate Rice. Los Baños, IRRI, 1976. p.471-494. 